Check for updates

Cite this: RSC Adv., 2018, 8, 4895

Received 5th November 2017

Accepted 15th January 2018

DOI: 10.1039/c7ra12136a

rsc.li/rsc-advances

\section{A high-activity cobalt-based MOF catalyst for $[2+2+2]$ cycloaddition of diynes and alkynes: insights into alkyne affinity and selectivity control $\uparrow$}

\author{
Fen Xu, (D) Xiao-Ju Si, Xiao-Ning Wang, Hao-Dong Kou, Di-Ming Chen, \\ Chun-Sen Liu (D)* and Miao Du (iD *
}

This work develops a highly efficient metal-organic framework (MOF) catalyst for the straightforward synthesis of functionalized benzenes via [2 $+2+2]$ cycloaddition. As efficient cooperative catalyst for such reactions, Co-MOF-1, shows great sustainability and efficiency. This new catalytic system can lead to the generation of a series of structurally diverse benzenes in good to excellent yields (up to 95\%).
Cycloaddition is a promising strategy used to develop a new synthetic methodology with high atom economy, providing efficient routes to construct various chemical bonds resulting in molecular complexity. ${ }^{1}$ For example, the $[2+2+2]$ cycloaddition of diynes and alkynes has been a powerful tool for the synthesis of functionalized benzenes in one step. ${ }^{2} \mathrm{~A}$ variety of transition metal catalysts, including $\mathrm{Rh},{ }^{3} \mathrm{Ru},{ }^{4} \mathrm{Pd}^{5}{ }^{5} \mathrm{Ir}^{6}$ and $\mathrm{Ni}^{7}$ have shown their capacity for $[2+2+2]$ annulations. However, in this connection, three crucial problems need to be resolved. (1) The competing dimerization or trimerization remains a challenging issue for $[2+2+2]$ cycloaddition with high selectivity. (2) These unrecoverable homogeneous catalysts will take a major responsibility for energy waste and environmental pollution. (3) The sensitivity to air or moisture for the known catalysts may greatly reduce the reaction efficiency and make the operation complicated. As a result, the development of easily separable and recoverable heterogeneous catalysts is of great significance and interest in this respect.

Metal-organic frameworks (MOFs) represent a rising class of porous crystalline materials with exceptional surface areas and uniformly dispersed metal ions. ${ }^{8}$ Such inherent properties make MOFs as advanced materials for gas storage and separation, ${ }^{9}$ drug delivery, ${ }^{10}$ heterogeneous catalysis, ${ }^{11}$ and so on. Recently, we have designed a series of MOFs materials with diverse pore shapes, sizes and compositions for targeted applications ${ }^{12}$ and also developed diversified metal-catalyzed cycloadditions involving alkynes. ${ }^{13}$ Thus, it will be anticipated to explore the potentials of MOFs as the new-type catalysts for cycloadditions, which may avoid the restrictions for the known examples. Notably, Co(I) or $\mathrm{Co}(\mathrm{II}) /$ additive $^{14}$ catalytic system has

College of Material and Chemical Engineering, Zhengzhou University of Light Industry, Zhengzhou 450002, China.E-mail: chunsenliu@zzuli.edu.cn; dumiao@zzuli.edu.cn $\dagger$ Electronic supplementary information (ESI) available. CCDC 1491616-1491623. For ESI and crystallographic data in CIF or other electronic format see DOI: $10.1039 / \mathrm{c} 7 \mathrm{ra12136a}$ shown activity in $[2+2+2]$ cycloaddition, though the dimerization or trimerization of terminal diynes usually occurs. ${ }^{15} \mathrm{On}$ this account, a porous MOF $\left[\mathrm{Co}_{2}(\mathrm{HCOO})_{2}(\mathrm{CPT})_{2}\right](\mathrm{NMF})_{5}\left(\mathrm{H}_{2} \mathrm{O}\right)_{2}$ (Co-MOF-1) with high affinity of acetylene was successfully constructed based on a bi-functional ligand 4-(4carboxyphenyl)-1,2,4-triazole (HCPT). ${ }^{16}$ As a result, a variety of benzene derivatives can be obtained via Co-MOF catalyzed $[2+2+2]$ cycloaddition in high yields with great tolerance of substrates and the crystalline defect of catalyst will account for the significant selectivity of the reactions (Scheme 1).

The Co-MOF-1 was harvested by reaction of $\mathrm{Co}\left(\mathrm{NO}_{3}\right)_{2} \cdot 6 \mathrm{H}_{2} \mathrm{O}$ and HCPT in NMF-water. Single-crystal X-ray diffraction analysis indicates that Co-MOF-1 crystallizes in the trigonal space group $R \overline{3} c .{ }^{16} \mathrm{~A}$ mentionable structural feature is the presence of distorted octahedral cages with the inner diameter of $7.9 \AA$, constituted by twelve $\mathrm{Co}(\mathrm{II})$ and twelve $\mathrm{CPT}^{-}$for each cage (Fig. 1a and $\mathrm{S} 2 \uparrow$ ). The octahedral cages are sequentially extended via sharing the trigonal windows. As a result, the 3D framework displays 1D hexagonal channels along $a$ axis with the pore diameter of $5.4 \AA$ (Fig. 1b, S3 and S4 $\dagger$ ) and the available void of $16835 \AA^{3}$, corresponding to $48.6 \%$ of the crystal volume $\left(34647.6 \AA^{3}\right)$.

The porosity of Co-MOF-1 was confirmed by $\mathrm{N}_{2}$ sorption at $77 \mathrm{~K}$. The $\mathrm{CH}_{2} \mathrm{Cl}_{2}$-exchanged Co-MOF-1 was activated at $70^{\circ} \mathrm{C}$ to afford the desolvated material Co-MOF-1' (Fig. S5 and S6 $†$ ).

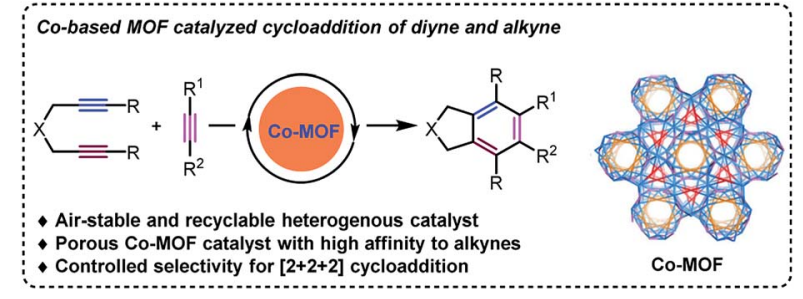

Scheme 1 Catalytic strategy for [2+2+2] cycloaddition in this work. 
a)
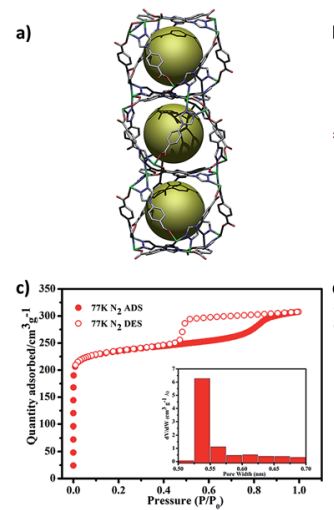

b)


Fig. 1 (a) The serial octahedral cages in Co-MOF-1. (b) The 3D framework of Co-MOF-1 with 1D channels running along a axis. (c) $\mathrm{N}_{2}$ sorption isotherm at $77 \mathrm{~K}$ for Co-MOF-1' (inset: pore size distribution plots). (d) $\mathrm{C}_{2} \mathrm{H}_{2}$ adsorption isotherms of Co-MOF-1' at 273 and $298 \mathrm{~K}$.

Notably, Co-MOF-1' shows an initial type-I adsorption isotherm, as a typical microporous material and then, a type-IV adsorption with obvious hysteresis and a significant portion of the mesopore volume of $0.46 \mathrm{~cm}^{3} \mathrm{~g}^{-1}$ (Fig. 1c). This can be a consequence of the dissociation of $\mathrm{Co}$ (II) ions and formation of defect sites in lattice. ${ }^{17}$ The maximal $\mathrm{N}_{2}$ uptake is $307 \mathrm{~cm}^{3} \mathrm{~g}^{-1}$, corresponding to a BET surface area of $947 \mathrm{~m}^{2} \mathrm{~g}^{-1}$ and pore diameter of 5.4 $\mathrm{A}$. The pore size distribution is consistent with the observation from its crystal structure. The combination of high porosity and defect sites in Co-MOF-1' promotes us to investigate its affinity toward acetylene, showing a high $\mathrm{C}_{2} \mathrm{H}_{2}$ adsorption capability (Fig. 1d) of $178 \mathrm{~cm}^{3} \mathrm{~g}^{-1}$ at $273 \mathrm{~K}$ and $1 \mathrm{bar}$ and $120 \mathrm{~cm}^{3} \mathrm{~g}^{-1}$ at $298 \mathrm{~K}$ and 1 bar. The isosteric heat of sorption $\left(Q_{\mathrm{st}}\right)$ for $\mathrm{C}_{2} \mathrm{H}_{2}$ molecule was calculated to evaluate the affinity between $\mathrm{C}_{2} \mathrm{H}_{2}$ and Co-MOF-1 (Fig. S7 and S8 $\dagger$ ). The result shows a high $Q_{\text {st }}$ value of $36 \mathrm{~kJ} \mathrm{~mol}^{-1}$ at zero loading, revealing a preferred binding capacity for $\mathrm{C}_{2} \mathrm{H}_{2}$ compared with the reported MOFs without high density of active sites $\left(Q_{\text {st }}\right.$ values: $\left.13.3-32.0 \mathrm{~kJ} \mathrm{~mol}^{-1}\right) .{ }^{18}$

Catalysis of $[2+2+2]$ cycloaddition by Co-MOF-1 was initiated from a terminal NTs-diyne $\mathbf{1 a}$ and phenylacetylene $\mathbf{2 a}$ (Table 1), in the presence of $6 \mathrm{~mol} \%$ 1,3-bis(diphenylphos phino)propane (dppp) and $10 \mathrm{~mol} \% \mathrm{Zn}$ powder in 1,2-dichloroethane (DCE). It is interesting that 3aa can be obtained directly in $40 \%$ yield after reaction at $80{ }^{\circ} \mathrm{C}$ for $24 \mathrm{~h}$ (entry 1 ). The yield was enhanced to $59 \%$ when Co-MOF-1 ${ }^{\prime}$ was used and higher yield was achieved in the presence of 4 equiv. of phenylacetylene (entries 2 and 3). Subsequent tests indicated that reducing the temperature was greatly to the disadvantage of annulation (entries 5 and 6) and a control experiment illustrated that dppp was necessary for this transformation (entry 7 ). In addition, decreasing the loading of dppp also sharply cut down the yield of target product (entries 3 and 8). It was also found that the transformation was dramatically affected by the catalyst, and the combination of $\mathrm{Co}\left(\mathrm{NO}_{3}\right)_{2}$ and dppp was incompetent to produce 3aa in only $12 \%$ yield (entry 9 ). 3aa was not detected in the absence of $\mathrm{Zn}$ powder (entry 10). The airstable and efficient Co-MOF-1' ${ }^{\prime}$ catalyst can be separated and recycled that makes it much sustainable compared to known examples. Therefore, the optimal reaction conditions were
Table 1 Optimization of reaction conditions ${ }^{a}$

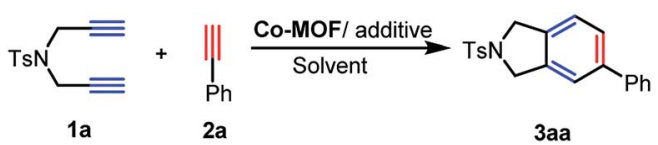

\begin{tabular}{llll}
\hline Entry & Catalyst & Temp. $\left({ }^{\circ} \mathrm{C}\right)$ & Yield $^{b}(\%)$ \\
\hline 1 & Co-MOF-1 $^{\prime}$ & 80 & 40 \\
2 & Co-MOF-1 $^{\prime}$ & 80 & 59 \\
$3^{c}$ & Co-MOF-1' $^{\prime}$ & 80 & 86 \\
$4^{d}$ & Co-MOF-1' $^{\prime}$ & 80 & 28 \\
5 & Co-MOF-1 $^{\prime}$ & 40 & Trace \\
6 & Co-MOF-1 $^{\prime}$ & RT & Trace \\
$7^{e}$ & Co-MOF-1 $^{\prime}$ & 80 & Trace \\
$8^{c, f}$ & Co-MOF-1' $^{g}$ & 80 & 60 \\
$9^{g}$ & Co(NO $\left._{3}\right)_{2}$ & 80 & 12 \\
$10^{h}$ & Co-MOF-1 $^{\prime}$ & 80 & N.D
\end{tabular}

${ }^{a}$ Reaction conditions: diyne $\mathbf{1 a}(0.25 \mathrm{mmol})$, phenylacetylene 2a (2 equiv., $0.5 \mathrm{mmol}$ ), Co-MOF (10 $\mathrm{mg})$, dppp ( $6 \mathrm{~mol} \%)$, $\mathrm{Zn}$ powder $(10 \mathrm{~mol} \%)$ and DCE $(2 \mathrm{~mL})$ at $80{ }^{\circ} \mathrm{C}$ for $24 \mathrm{~h} .{ }^{b}$ Isolated yield. ${ }^{c} \mathbf{2 a}$ (4 equiv.). ${ }^{d}$ Co-MOF-1' (1 $\left.\mathrm{mg}\right) .{ }^{e}$ No dppp. ${ }^{f}$ dppp (3 mol\%). ${ }^{g} \mathrm{Co}\left(\mathrm{NO}_{3}\right)_{2}(5 \mathrm{~mol} \%)$, dppp $(6 \mathrm{~mol} \%)$ and $\mathrm{Zn}$ powder $(10 \mathrm{~mol} \%) .{ }^{h} \mathrm{In}$ the absence of $\mathrm{Zn}$ powder, N.D (not detected).

determined as Co-MOF-1' (10 mg), dppp (6 mol\%) and $\mathrm{Zn}$ powder $(10 \mathrm{~mol} \%)$ in DCE $(2.0 \mathrm{~mL})$ at $80{ }^{\circ} \mathrm{C}$ for $24 \mathrm{~h}$.

The generality and functional-group tolerance was explored by different substituted alkynes. A broad range of phenylacetylenes with either electron-donating or -withdrawing groups, could react smoothly with NTs-diyne 1a and enable the formation of substituted benzenes 3aa-ad and 3af-ah in 86-95\% yields (Scheme 2). Initially, 1a was treated with 2 a,



Scheme 2 Formation of benzenes from diynes $1 a-j$ and alkynes $2 a-j$. 
Co-MOF-1' and dppp in DCE. This led to the formation of 3aa in $86 \%$ isolated yield. As illustrated, aromatic alkynes bearing Meand $\mathrm{F}$ - groups served as the most proper substrates in this case and showed unconspicuous effect on the reaction efficiency (Scheme 2, 3ad and 3ag). In contrast, the ortho-substituted 1-ethynyl-2-methyl benzene showed extremely poor reactivity (Scheme 2, 3ae). Further, para- and meta-substitution was also tolerated, while a slight reduced yield was found for aromatic alkyne with meta-substitution (Scheme 2, 3ag and 3ah). Notably, the reaction of pharmaceutically important aromatic substituted alkynes, aiming at introducing fluorine and/or fluorinated building blocks into the aromatic ring, has remained a challenge thus far. Herein, $2 \mathbf{g}$ and $2 \mathbf{h}$ delicately decorated by fluorine were revealed as meaningful substrates as well, affording the corresponding products $\mathbf{3 a g}$ and $\mathbf{3 a h}$ in $93 \%$ and $86 \%$ yields. However, sterically hindered internal alkynes $2 \mathbf{i}$ and $2 \mathbf{j}$ were incompatible, forming dimer or trimer of diynes as side-products, where the bulky phenyl groups may prevent the contact of substrates with the active sites of catalyst.

Subsequently, the scope of this reaction with respect to diynes was further extended. A variety of $\mathrm{N}$-based diynes, ranging from $N, N$-di(prop-2-yn-1-yl)benzenesulfonamide 1c with electronically diverse groups on phenyl ring (1b-1d), $N$-benzyl- $N$-(prop-2-yn-1-yl)prop-2-yn-1-amine 1f, to $N, N$ di(prop-2-yn-1-yl) methanesulfonamide 1g, was used in this catalytic system. The corresponding products were obtained in 84-95\% yields (Scheme 2, 3ba-ga), which are similar to those reactions with NTs-based diyne 1a. Notably, the electronic nature of phenyl ring for N-based diynes turned out to be significant for the cyclization. With Co-MOF-1 ${ }^{\prime}$ and dppp in the presence of $\mathrm{Zn}$ powder, 3 ba was achieved in a yield of $95 \%$, whereas 3 aa was produced in $86 \%$ yield. Significantly, cycloadduct 3da with F- substituent was obtained in high yield of 93\%. In accordance with the observation that steric factor intensively influences the reactivity of alkyne substrates, internal diyne $N, N$-di(but-2-yn-1-yl)-4-methylbenzene sulfonamide $1 \mathrm{~h}$ was failed to afford benzene scaffold $3 \mathrm{ha}$. This work was also highlighted by substrate of ester tethered diyne, affording corresponding product $3 \mathbf{i a}$ in $87 \%$ yield. In addition to N-based or ester-tethered diyne, dipropargyl ether showing high reactivity for dimerization to arene byproduct, ${ }^{19}$ cyclized with 2a to afford the corresponding benzo[c]furan $3 \mathbf{j a}$ in moderate yield (Scheme 2).

The major advantage of heterogeneous catalysts is their reutilization, which is one of the most important indexes to evaluate the performance of catalyst effect and stability along the catalytic cycle. Recycling experiments were performed on Co-MOF-1' for the annulation of $\mathbf{1 b}$ and $\mathbf{2 a}$. The catalyst was recycled for five runs with no decrease of activity, giving 93-95\% isolated yields (Fig. S9a†). After each case, the recovered Co-MOF-1' catalyst was characterized by powder X-ray diffraction (PXRD) technique (Fig. S9b $\dagger$ ). Notably, even after the fifth run, the PXRD pattern evidently confirmed that the catalyst remained excellent crystallinity and was not damaged in the catalytic process.

To further shed some light on the reaction mechanism, auxiliary experiment was designed and conducted to probe the active species of this transformation. As the presence of $\mathrm{Co}$ (II) ions in the initial reaction solution $\left(25.5 \mathrm{mg} \mathrm{L}^{-1}\right)$ was detected by ICP-MS, we suspected that such a reaction would begin with a sluggish release of $\mathrm{Co}(\mathrm{II})$ due to the crystal defect of catalyst, which was then reduced by Zn powder to give $\mathrm{Co}(\mathrm{I})$ species. The active $\mathrm{Co}(\mathrm{I})$ surrounded the surface of Co-MOF-1' $\mathbf{1}^{\prime}$ material to facilely capture the neighboring diyne A via ligand exchange, forming a 5-membered metallacyclopentadiene intermediate $\mathbf{B}$ through traditional oxidative addition. However, attempt to isolate the species $\mathbf{B}$ was failed. After that, $\mathbf{B}$ will either undergo alkyne insertion to form 7-membered azametallacycle $\mathbf{C}$ or $[4+2]$ annulation to produce $\mathbf{D}$, resulting in benzenes via reductive elimination to afford the final product $\mathbf{E}$ and also regenerate $\mathrm{Co}(\mathrm{I})$ for the next catalytic cycle (Fig. 2).

To confirm the catalytic mechanism, two control experiments were further discussed. First, subjecting $N, N$-di(but-2-yn1-yl)-4-methylbenzenesulfonamide $\mathbf{1 h}$ with $\mathbf{2 a}$ to this annulation failed to deliver the target product. In fact, $\mathbf{1 h}$ was largely retained after reaction, revealing that higher steric internal diyne will suppress the fast access to active $\mathrm{Co}(\mathrm{I})$ species on the surface of catalyst (eq. 1 in Fig. 3). Then, a compensatory experiment involving the coupling of terminal diyne 1a with alkyne $2 \mathbf{j}$ showed that the dimer of $\mathbf{1 a}$ was achieved instead of [2 $+2+2]$ annulation. This reveals that the internal alkyne will hardly get close to the active Co(I) due to the low affinity to Co-MOF-1' (eq. 2 compared with eq. 3 and eq. 4 in Fig. 3 ). Thus,

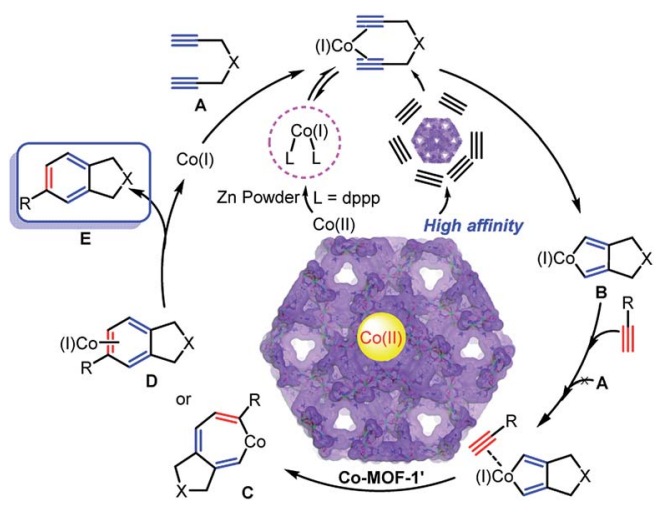

Fig. 2 Proposed mechanism for the transformation.

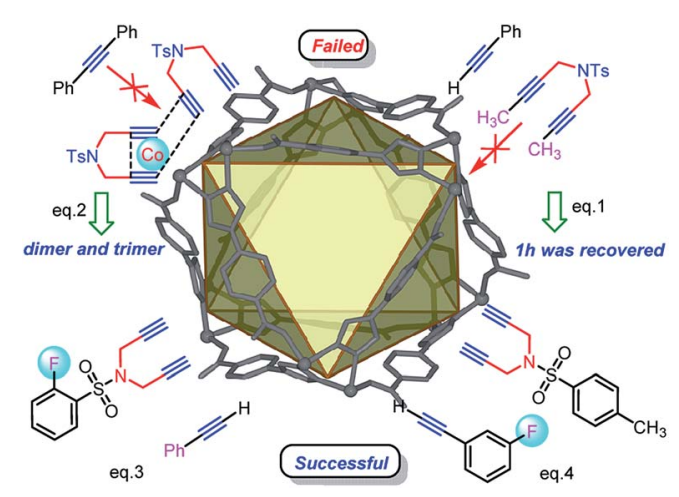

Fig. 3 The auxiliary verification experiments for catalytic mechanism. 
it can be concluded that the cycloaddition would proceed favorably near the catalyst surface with "spot-activated cobalt", allowing only high-affinity alkynes to approach the metal center and thus high selectivity can be realized for cycloadditions. This strategy also provided the potentials for the development of template and precise catalysts.

\section{Conclusions}

In conclusion, a 3D $\mathrm{Co}(\mathrm{II})$-based $\mathrm{MOF}$ was designed and prepared, showing serial window-sharing octahedral cages and 1D hexagonal channels. The activated Co-MOF-1' has high affinity toward acetylene and serves as a heterogeneous and recoverable catalyst for $[2+2+2]$ cycloaddition to afford highly substituted benzenes with remarkable efficiency, selectivity, and functional group tolerance. Notably, this transformation is also compatible with aromatic alkynes with fluorine substituent and thus provided products with potential pharmaceutical activity. Co-MOF-1' with high alkyne affinity and "activated cobalt" can preclude the fast approach of sterically hindered substrates to the active sites, which may well account for the selectivity of achieved products. The results witnessed the great success of Co-MOF-1' as catalyst for annulation and encouraged further developments of new MOFs catalysts for expedient synthetic transformations.

\section{Conflicts of interest}

There are no conflicts to declare.

\section{Acknowledgements}

We are grateful to the support from the National Natural Science Foundation of China (21471134, 21571158, and 21701148).

\section{Notes and references}

1 (a) S. Perreault and T. Rovis, Chem. Soc. Rev., 2009, 38, 3149; (b) H. Pellissier and H. Clavier, Chem. Rev., 2014, 114, 2775; (c) D. M. Kuznetsov, O. A. Mukhina and A. G. Kutateladze, Angew. Chem., Int. Ed., 2016, 55, 6988; (d) G. M. Torres, J. S. Quesnel, D. Bijou and B. A. Arndtsen, J. Am. Chem. Soc., 2016, 138, 7315; (e) C. Ni and X. Tong, J. Am. Chem. Soc., 2016, 138, 7872; (f) Y. Deng, L. A. Massey, Y. R. Núñez, H. Arman and M. P. Doyle, Angew. Chem., Int. Ed., 2017, 56, 12292; (g) R. L. Sahani and R.-S. Liu, Angew. Chem., Int. Ed., 2017, 56, 12736; (h) S. C. Schmid, I. A. Guzei and J. M. Schomaker, Angew. Chem., Int. Ed., 2017, 56, 12229; (i) J.-L. Shih, S. Jansone-Popova, C. Huynh and J. A. May, Chem. Sci., 2017, 8, 7132; (j) L. Shen, K. Zhao, K. Doitomi, R. Ganguly, Y.-X. Li, Z.-L. Shen, H. Hirao and T.-P. Loh, J. Am. Chem. Soc., 2017, 139, 13570.

2 (a) M. R. Shaaban, R. El-Sayed and A. H. M. Elwahy, Tetrahedron, 2011, 67, 6095; (b) S. Kotha, E. Brahmachary and K. Lahiri, Eur. J. Org. Chem., 2005, 4741; (c) H. F. Jónsson, S. Evjen and A. Fiksdahl, Org. Lett., 2017, 19, 2202; (d) H. Ueda, K. Masutomi, Y. Shibata and K. Tanaka,
Org. Lett., 2017, 19, 2913; (e) D. Bhatt, H. Chowdhury and A. Goswami, Org. Lett., 2017, 19, 3350; (f) D. Brenna, M. Villa, T. Gieshoff, F. Fischer, M. Hapke and A. J. Wangelin, Angew. Chem., Int. Ed., 2017, 56, 8451.

3 (a) R. Shintani, C. Takagi, T. Ito, M. Naito and K. Nozaki, Angew. Chem., Int. Ed., 2015, 54, 1616; (b) R. P. Kaiser, F. Hessler, J. Mosinger, I. Císařová and M. Kotora, Chem.Eur. J., 2015, 21, 13577.

4 (a) R. Karmakar, S. Y. Yun, J. Chen, Y. Xia and D. Lee, Angew. Chem., Int. Ed., 2015, 54, 6582; (b) J. Jacquet, A. Auvinet, A. K. Mandadapu, M. Haddad, V. Ratovelomanana-Vidal and V. Micheleta, Adv. Synth. Catal., 2015, 357, 1387; (c) H. Chowdhury and A. Goswami, Org. Biomol. Chem., 2017, 15, 5824.

5 P. J. Parsons, D. R. Jones, A. C. Padgham, L. A. T. Allen, C. S. Penkett, R. A. Green and A. J. P. White, Chem.-Eur. J., 2016, 22, 3981.

6 G. Onodera, Y. Shimizu, J. Kimura, J. Kobayashi, Y. Ebihara, K. Kondo, K. Sakata and R. Takeuchi, J. Am. Chem. Soc., 2012, 134, 10515.

7 A. Thakur and J. Louie, Acc. Chem. Res., 2015, 48, 2354.

8 (a) P.-Z. Li, X.-J. Wang, S. Y. Tan, C. Yang, H. Chen, J. Liu, R. Zou and Y. Zhao, Angew. Chem., Int. Ed., 2015, 54, 12748; (b) H. Deng, S. Grunder, K. E. Cordova, C. Valente, H. Furukawa, M. Hmadeh, F. Gándara, A. C. Whalley, Z. Liu, S. Asahina, H. Kazumori, M. O'Keeffe, O. Terasaki, J. F. Stoddart and O. M. Yaghi, Science, 2012, 336, 1018; (c) J.-S. Qin, D.-Y. Du, W. Guan, X.-J. Bo, Y.-F. Li, L.-P. Guo, Z.-M. Su, Y.-Y. Wang, Y.-Q. Lan and H.-C. Zhou, J. Am. Chem. Soc., 2015, 137, 7169; (d) A. Schoedel, M. Li, D. A. Schoedel, M. Li, D. Li, M. O'Keeffe and O. M. Yaghi, Chem. Rev., 2016, 116, 12466; (e) Y. Long, L. Xiao, Q. Cao, X. Shi and Y. Wang, Chem. Commun., 2017, 53, 10831; (f) Y.-S. Wei, X.-P. Hu, Z. Han, X.-Y. Dong, S.-Q. Zang and T. C. W. Mak, J. Am. Chem. Soc., 2017, 139, 3505.

9 Y. He, W. Zhou, G. Qian and B. Chen, Chem. Soc. Rev., 2014, 43, 5657.

10 H. Zheng, Y. Zhang, L. Liu, W. Wan, P. Guo, A. M. Nyström and X. Zou, J. Am. Chem. Soc., 2016, 138, 962.

11 (a) W.-Y. Gao, H. Wu, K. Leng, Y. Sun and S. Ma, Angew. Chem., Int. Ed., 2016, 55, 5472; (b) J. Liu, L. Chen, H. Cui, J. Zhang, L. Zhang and C.-Y. Su, Chem. Soc. Rev., 2014, 43, 6011; (c) X.-L. Lv, K. Wang, B. Wang, J. Su, X. Zou, Y. Xie, J.-R. Li and H.-C. Zhou, J. Am. Chem. Soc., 2017, 139, 211; (d) Y.-B. Huang, J. Liang, X.-S. Wang and R. Cao, Chem. Soc. Rev., 2017, 46, 126; (e) J. Liang, R.-P. Chen, X.-Y. Wang, T.-T. Liu, X.-S. Wang, Y.-B. Huang and R. Cao, Chem. Sci., 2017, 8, 1570.

12 (a) M. Du, C.-P. Li, C.-S. Liu and S.-M. Fang, Coord. Chem. Rev., 2013, 257, 1282; (b) M. Du, C.-P. Li, M. Chen, Z.-W. Ge, X. Wang, L. Wang and C.-S. Liu, J. Am. Chem. Soc., 2014, 136, 10906; (c) M. Du, X. Wang, M. Chen, C.-P. Li, J.-Y. Tian, Z.-W. Wang and C.-S. Liu, Chem.-Eur. J., 2015, 21, 9713; (d) D.-M. Chen, J.-Y. Tian, C.-S. Liu and M. Du, Chem. Commun., 2016, 52, 8413; (e) D.-M. Chen, J.-Y. Tian, M. Chen, C.-S. Liu and M. Du, ACS Appl. Mater. Interfaces, 2016, 8, 18043. 
13 (a) F. Xu, C. Wang, D. Wang, X. Li and B. Wan, Chem.-Eur. J., 2013, 19, 2252; (b) F. Xu, C. Wang, H. Wang, X. Li and B. Wan, Green Chem., 2015, 17, 799.

14 (a) A. A. More and C. V. Ramana, J. Org. Chem., 2016, 81, 3400; (b) Y. Sugiyama, R. Kato, T. Sakurada and S. Okamoto, J. Am. Chem. Soc., 2011, 133, 9712.

15 N. Saino, F. Amemiya, E. Tanabe, K. Kase and S. Okamoto, Org. Lett., 2006, 8, 1439.

16 D.-M. Chen, X.-H. Liu, J.-Y. Tian, J.-H. Zhang, C.-S. Liu and M. Du, Inorg. Chem., 2017, 56, 14767.
17 H. Wu, Y. S. Chua, V. Krungleviciute, M. Tyagi, P. Chen, T. Yildirim and W. Zhou, J. Am. Chem. Soc., 2013, 135, 10525.

18 (a) Y. He, Z. Zhang, S. Xiang, F. R. Fronczek, R. Krishna and B. Chen, Chem. Commun., 2012, 48, 6493; (b) S. Xiang, W. Zhou, J. M. Gallegos, Y. Liu and B. Chen, J. Am. Chem. Soc., 2009, 131, 12415; (c) J. Pang, F. Jiang, M. Wu, C. Liu, K. Su, W. Lu, D. Yuan and M. Hong, Nat. Commun., 2015, 6, 7575; (d) Y. He, R. Krishna and B. Chen, Energy Environ. Sci., 2012, 5, 9107.

19 R. Grigg, R. Scott and P. Stevenson, J. Chem. Soc., Perkin Trans. 1, 1988, 1357. 